\title{
An Assessment of Diurnal and Seasonal Cloud Cover Changes over the Hawaiian Islands Using Terra and Aqua MODIS*
}

\author{
MALLORY L. BARNES ${ }^{+}$AND TOMOAKI MIURA \\ Department of Natural Resource and Environmental Management, University of Hawai' ${ }^{\prime}$ at Mānoa, Honolulu, Hawaii
}

THOMAS W. GiAMBELLUCA

Department of Geography, University of Hawai' $i$ at Mānoa, Honolulu, Hawaii

(Manuscript received 2 February 2015, in final form 1 October 2015)

\begin{abstract}
A comprehensive understanding of the spatial, seasonal, and diurnal patterns in cloud cover frequency over the Hawaiian Islands was developed using high-resolution image data from the National Aeronautics and Space Administration's Moderate Resolution Imaging Spectroradiometer (MODIS) sensors aboard the Terra and Aqua satellites. The Terra and Aqua MODIS cloud mask products, which provide the confidence that a given 1-km pixel is unobstructed by cloud, were obtained for the entire MODIS time series (10-plus years) over the main Hawaiian Islands. Monthly statistics were generated from the daily cloud mask data, including mean cloud cover frequency at the four daily overpass times. The derived mean cloud cover frequency showed patterns that were generally consistent with the known distribution of mean rainfall and with the results from previous studies. Cloud cover frequency was the highest over land areas with elevations between the lifting condensation level $(\sim 600 \mathrm{~m})$ and the mean height of the trade wind inversion (TWI) base $(\sim 2200 \mathrm{~m})$, especially for the windward (northeastern) mountain slopes. Above the TWI, cloud frequency decreased sharply with elevation. Irrespective of season, cloud cover frequency was generally higher in the afternoon than in the morning and higher in daytime than at nighttime although these trends varied spatially. The dry season months (May-October) were less cloudy than the wet season months (November-April) at nighttime. The analysis also revealed a local December-January minimum in the annual cycle of cloud cover frequency. The monthly time series produced in this study is the first high-spatial-resolution cloud cover dataset in Hawaii.
\end{abstract}

\section{Introduction}

Knowledge of cloud cover frequency is essential for climate science studies, effective management of natural resources, and remote sensing applications. Clouds have a strong but variable impact on the surface energy budget; feedbacks associated with warming-related

\footnotetext{
* Supplemental information related to this paper is available at the Journals Online website: http://dx.doi.org/10.1175/JCLI-D-150088.s1.

${ }^{+}$Current affiliation: School of Natural Resources and the Environment, The University of Arizona, Tucson, Arizona.

Corresponding author address: Mallory L. Barnes, School of Natural Resources and the Environment, The University of Arizona, 1064 East Lowell Street, Tucson, AZ 85721.

E-mail: mallorybarnes@email.arizona.edu
}

cloud cover changes could potentially amplify or reduce the effects of increased $\mathrm{CO}_{2}$ in the atmosphere (Wylie et al. 2005; Pincus et al. 2012). Clouds reflect incoming solar radiation, thereby reducing daytime temperature and the evapotranspiration (ET) demand of plants (Ackerman et al. 1998). Clouds can also reduce net longwave radiation loss, thus warming the surface, especially at night. With regard to ET estimation, cloud cover frequency can be used to estimate net radiation in the absence of ground-based observations over land (Running et al. 1989). Cloud cover frequency information is a requirement for the production of highquality land remote sensing products as retrievals of surface parameters, such as land surface temperature and leaf area index (LAI), are impeded by cloud cover (e.g., Sano et al. 2007; Ju and Roy 2008).

Regardless of its importance, previous studies on cloud cover patterns over the Hawaiian Islands were 
limited in the spatial extent and temporal coverage as a result of the lack of appropriate datasets. Schroeder et al. (1977) investigated cloudiness on the island of Hawaii for a 2-week period, 17-31 July 1976, using Synchronous Meteorological Satellite-2 (SMS-2) geostationary satellite images and Very High Resolution Radiometer (VHRR) images. The spatial resolution of the cloudiness data was $1 \mathrm{~km}$ for daytime and $8 \mathrm{~km}$ at night. Soon after the advent of Moderate Resolution Imaging Spectroradiometer (MODIS) aboard the National Aeronautics and Space Administration's (NASA) Earth Observing System (EOS) Terra and Aqua satellites, Yang et al. (2008a,b) used the MODIS 1-km daily cloud mask products (Ackerman et al. 1998; Frey et al. 2008) and determined daytime cloud cover frequency over and downwind of the islands of Kauai and Hawaii. Their studies have shown that the MODIS products have the high spatial resolution $(1 \mathrm{~km})$ necessary to depict the spatial characteristics of cloud cover over the Hawaiian Islands in detail, but they only used the products from June to August of 2004 and 2005.

The objective of this study was to conduct a comprehensive analysis of cloud cover frequencies for Hawaii using high-resolution $(1 \mathrm{~km}$ and four times daily) cloud cover data from the Terra and Aqua MODIS satellite sensors, and to determine how spatial patterns of cloudiness vary diurnally and seasonally over the islands. At the commencement of this study, the MODIS data record had surpassed 10 years, providing sufficient length to determine climatologically significant mean annual and diurnal cycles in cloud cover frequency.

\section{Materials and methods}

\section{a. Description of study area}

The study area, the main Hawaiian Islands, is situated in the central, tropical North Pacific Ocean $\left(18-22^{\circ} \mathrm{N}\right.$, $154-161^{\circ} \mathrm{W}$ ) (Fig. 1). Formed by volcanic eruptions and subsequent erosion, the Hawaiian Islands have a varied topographic landscape, with smooth, moderately sloped mountains reaching $4000 \mathrm{~m}$ in height on the youngest island (Hawaii) and steep, highly dissected slopes on the oldest of the major islands (Kauai) (Fig. 1).

Hawaii has two seasons: dry "summer" from May to October and wet "winter" from November to April (Giambelluca et al. 1986, 2013). Topography and the trade winds significantly influence the local climate. The trade winds, easterly surface winds that are found in the tropics, blow persistently from the east-northeast (ENE) direction in Hawaii (Giambelluca and Schroeder 1998; Giambelluca et al. 2013). These winds result in orographic clouds and rain on the windward (northeast) slopes of mountains. The leeward (southwest) sides of mountains are generally drier.

Spatial patterns of climate in Hawaii are also strongly influenced by the trade wind inversion (TWI). Cloudproducing lifting of air-for example, orographic lifting along windward slopes-is halted at the height of this shallow stable layer, generally at about $2200 \mathrm{~m}$ MSL (Giambelluca and Schroeder 1998; Giambelluca et al. 2013). This results in very low precipitation and cloud cover at higher elevations. The lowest observed mean rainfall across the state is on the summits of the highest mountains, Mauna Kea and Mauna Loa (Giambelluca et al. 2013).

The diurnal cycle of rainfall and cloud cover over the Hawaiian Islands has been explored by Schroeder et al. (1977). Based on hourly rainfall data from 103 stations on the main Hawaiian Islands, Schroeder et al. (1977) summarized diurnal rainfall frequency patterns. They found that the time of the maximum chance of rain varied spatially and was from noon to early afternoon at many of the stations located on inland leeward mountain slopes of the island of Hawaii and the leeward sides of most of the islands. The diurnal cycle of cloudiness was derived from geostationary satellite images at 12 stations on the island of Hawaii for the month of July. Diurnal rainfall and cloudiness patterns were found to be highly variable and complex, largely based on local topography and aspect (Schroeder et al. 1977). Stations along the windward coast were characterized by a very pronounced nocturnal maximum in rainfall, but cloudiness at those stations had small diurnal variations. In contrast, those on the leeward side had large and very pronounced variations in both cloudiness and rainfall frequency with the late afternoon maxima in both (Schroeder et al. 1977).

\section{b. MODIS cloud mask product}

The Terra and Aqua MODIS level 2 cloud mask products (MOD35 and MYD35, respectively) were used in this study (Frey et al. 2008; Ackerman et al. 2015). Two MODIS sensors, one on each of NASA's Terra and Aqua satellites, are cross-track scanning radiometers and both in a near-polar sun-synchronous orbit at an altitude of $705 \mathrm{~km}$ (Platnick et al. 2003). The Terra and Aqua platforms have a 16-day repeat cycle, but the wide swath $(2330 \mathrm{~km})$ of MODIS provides near-global coverage twice a day: once at night and once during the day.

The MODIS cloud mask product provides the level of confidence that a particular 1-km (at nadir) pixel is unobstructed by cloud at the instant the image was acquired (Ackerman et al. 1998; Platnick et al. 2003; Ackerman et al. 2008; Frey et al. 2008). The detection of 
(a)

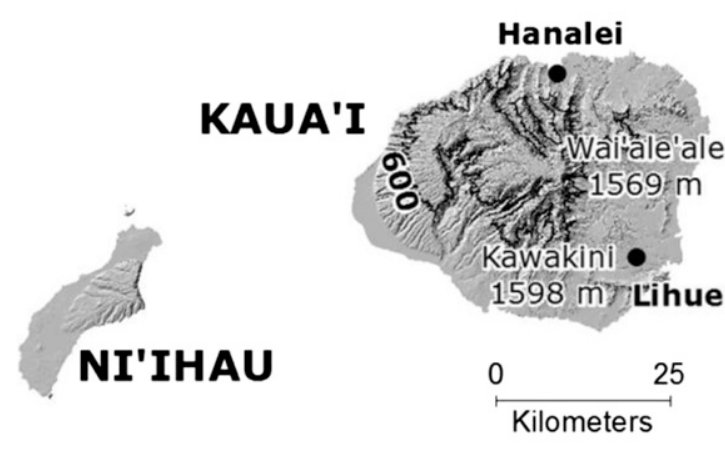

(b) O'AHU (c)

MOLOKA'I

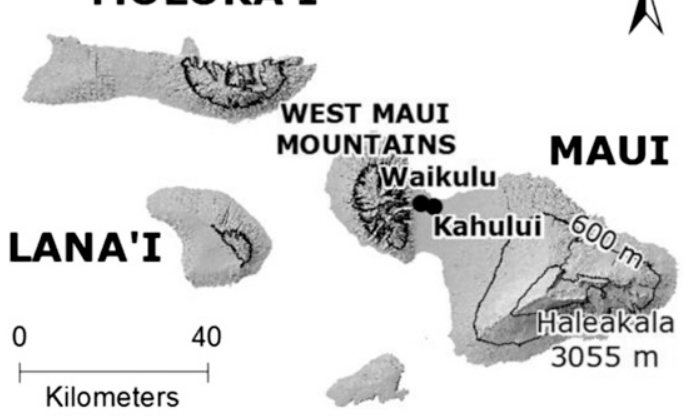

KAHO'OLAWE (d)

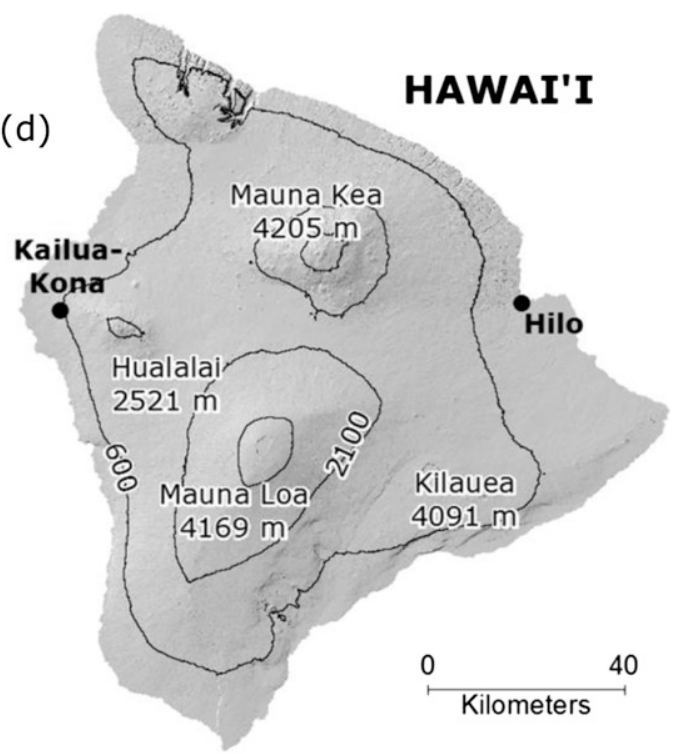

FIG. 1. Major geologic, geographic, and political features in the four counties in the state of Hawaii. Major mountain summits and major cities are labeled. (a) Kauai County, (b) Honolulu County, (c) Maui County, and (d) Hawaii County.

cloud is based on the contrast between the cloud and the background environment (e.g., land surface or atmosphere) in a given 1-km (at nadir) pixel, for which a combination of spectral threshold tests are employed using as many as 14 of the 36 MODIS spectral bands (Ackerman et al. 1998; Platnick et al. 2003; Frey et al. 2008). The particular series of spectral threshold tests applied to the field of view is determined by the surface type (land, water, snow/ice, desert, and coastline) and the solar illumination (day vs night) (Ackerman et al. 1998; Frey et al. 2008). Each individual test returns a confidence level from 1 (high confidence that pixel is clear) to 0 (high confidence of cloud) (Ackerman et al. 1998; Frey et al. 2008). The tests are grouped by type in order to maximize the independence of the spectral threshold tests and then the final cloud mask confidence $(Q)$ is calculated as the product of the minimum confidence levels from all groups (Ackerman et al. 1998, 2006; Frey et al. 2008). One of the following four confidence levels is assigned to the pixel based on the final cloud mask confidence: confident clear $(Q>0.99)$, probably clear $(0.99 \geq Q>0.95)$, uncertain/probably cloudy $(0.95 \geq Q>0.66)$, and cloudy $(Q \leq 0.66)$ (Frey et al. 2008; Ackerman et al. 2006). The cloud mask algorithm is clear-sky conservative in that if a pixel fails any single test, then the pixel is defined as cloud contaminated (Ackerman et al. 2006; Frey et al. 2008). In addition to the cloud mask scientific dataset, the MODIS cloud mask product has a corresponding quality assurance (QA) scientific dataset. The QA flags indicate the quality of various parameters in the cloud mask scientific dataset.

A preliminary comparison by Ackerman et al. (2006) of the MODIS cloud mask with ground-based micropulse 
lidar/millimeter-wavelength cloud radar (MPL/MMCR) indicated that the MODIS cloud detection algorithm agreed with MPL/MMCR $86 \%$ of the time when it was clear or probably clear, and $92 \%$ of the time when a cloud was present. Ackerman et al. (2008) compared coincident observations of the MODIS cloud mask with the Department of Energy's (DOE) Atmospheric Radiation Measurement (ARM) Program Active Remote Sensing of Cloud Locations (ARSCL) product retrievals at a Southern Great Plains site in Oklahoma. Agreement between the collocated MODIS and ARSCL observations was approximately $83 \%$ (Ackerman et al. 2008).

\section{c. Data collection and processing}

The 1-km cloud mask products (MOD35 and MYD35) over the major Hawaiian Islands (top: $22.503^{\circ} \mathrm{N}$, left: $160.5^{\circ} \mathrm{W}$, bottom: $18.75^{\circ} \mathrm{N}$, right: $154.497^{\circ} \mathrm{W}$ ) were obtained from NASA's Level 1 and Atmosphere Archive and Distribution System (LAADS) (https://ladsweb. nascom.nasa.gov/). The study used 11 years of data obtained from Terra MODIS (2001-11) and 9 years of data obtained from Aqua MODIS (2003-11). The mean daytime and nighttime overpass times over the study area were 1110 and 2240 HST (HST $+10=$ UTC), respectively, for Terra MODIS and 1350 HST and 0220 HST, respectively, for Aqua MODIS.

The cloud mask images were reprojected onto a 1-km $\left(0.083^{\circ}\right)$ geographic coordinate grid on the North American Datum of 1983 (NAD83) and subset to cover the major Hawaiian Islands using MODIS Reprojection Tool Swath (https://lpdaac.usgs.gov/tools/modis_reprojection_ tool_swath). The nearest-neighbor resampling method was used in the reprojection.

The reprojected and subset cloud mask data were then coded into the binary indicator of cloudy (1) or clear (0) from the four confidence levels. Two different encoding criteria were used, one for daytime scenes and the other for nighttime scenes, based on the suggestions in the MODIS user's guide for isolating cloudy scenes (Strabala 2008; Ackerman et al. 2006) and a consultation with the MODIS cloud mask team (R. A. Frey 2011, personal communication). For the daytime images, pixels designated as "confident cloudy" or "probably cloudy" by the MODIS cloud mask were considered "cloudy," and pixels designated as "confident clear" or "probably clear" by the MODIS cloud mask were considered "clear." Areas flagged as sun-glint regions by the MODIS cloud mask algorithm were not included. When the QA flags indicated low confidence in the cloud mask, the pixels were not included.

The nighttime encoding method was altered from the daytime method to remedy the problem of systematic nighttime overestimation of cloud frequency over the land (http://modis-atmos.gsfc.nasa. gov/MOD35_L2/qa.html; Yang et al. 2008a,b; R. A. Frey 2011, personal communication). The MODIS cloud detection algorithm relies on infrared data alone during nighttime, which caused nighttime overestimation of cloud cover over the Hawaiian Islands. In the nighttime algorithm, pixels designated as confident cloudy were considered cloudy and pixels designated as probably cloudy, confident clear, or probably clear by the MODIS cloud mask were considered clear. Overclouding occurred most frequently over land at elevations below $2000 \mathrm{~m}$, which was related to the nighttime land surface temperature test (SFCT). The SFCT compares gridded surface air temperatures from the Global Data Assimilation System (GDAS; $1^{\circ}$ spatial and 6-h temporal resolution) to observed $11-\mu \mathrm{m}$ brightness temperatures at elevations up to $2000 \mathrm{~m}$ (Frey et al. 2008). Therefore, if the surface temperature test was the only test to find cloud (pixels designated probably cloudy or cloudy), then the pixel was considered clear. The test did not appear to have performed well for the elevation range likely because of large variations in surface temperature for the elevation range of the Hawaiian Islands.

Monthly cloudiness statistics at each of the four overpass times were generated from the daily MOD35 and MYD35 binary cloudiness time series. They included mean, minimum, maximum, and standard deviation of cloud cover frequency at each pixel. For each month, daily cloud cover scenes were first processed into a monthly cloud cover frequency for each year in the time series $(2011,2010$, etc.). The means of these monthly frequencies (11 years for Terra MODIS and 9 years for Aqua MODIS) were then calculated. The resulting time series consisted of one cloud cover frequency map for each month for each of the four overpass times (12 mean monthly cloud cover frequency maps at four overpass times).

Annual, dry season, and wet season cloud cover frequency statistics were also obtained from the monthly values for each year by first calculating cloud cover frequency values for each year and then calculating means and standard errors (11 years for Terra MODIS and 9 years for Aqua MODIS).

\section{d. Data analysis}

Statistical difference tests were performed for the analysis of cloud cover frequency between the dry and wet seasons, and across overpass times. To compare cloud cover frequency in the dry and wet seasons, a one-way analysis of variance (ANOVA) was 

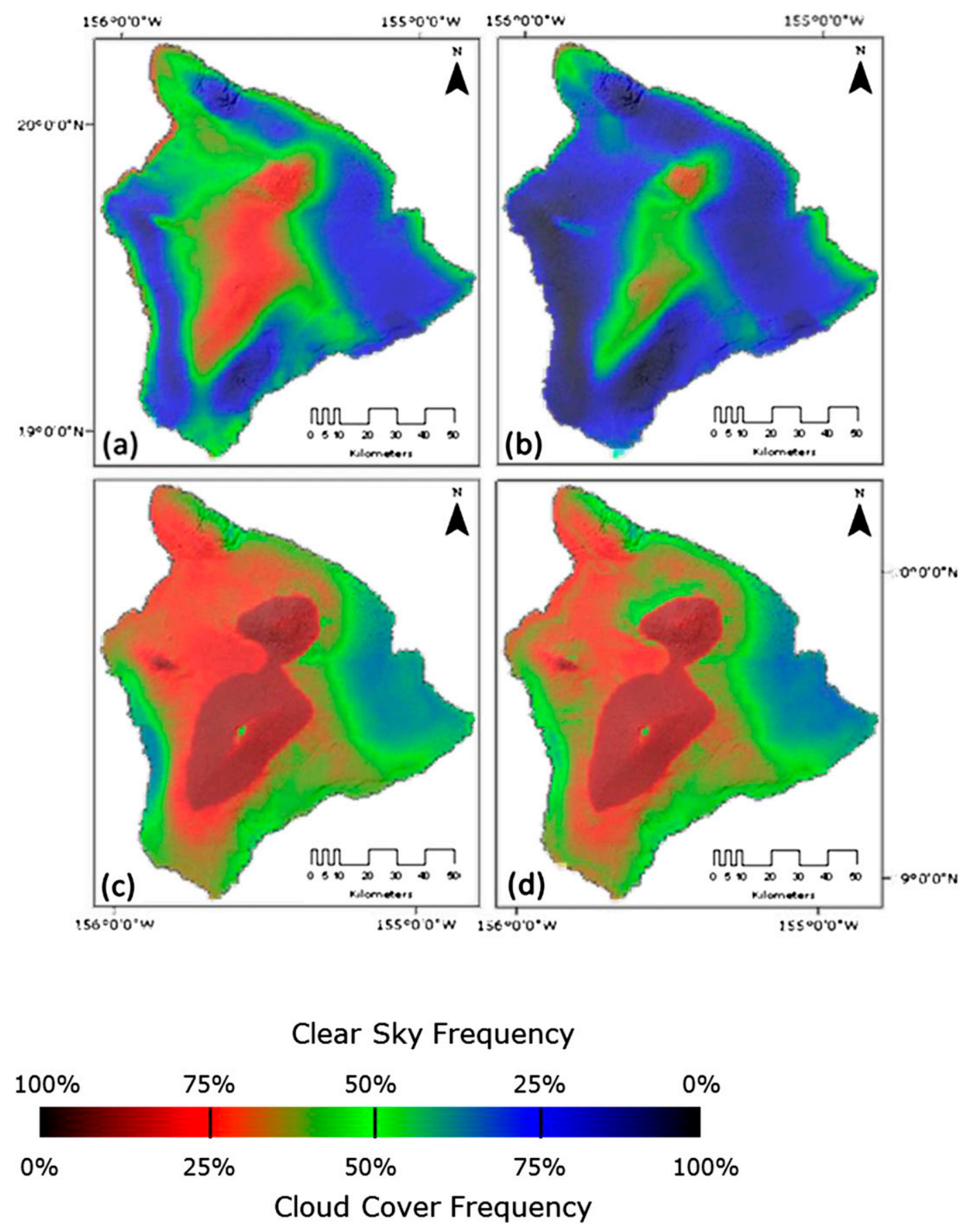

FIG. 2. Annual mean cloud cover at all four MODIS overpass times over Hawaii County. Red represents $100 \%$ clear sky, blue represents $100 \%$ cloud cover, and green represents 50\% cloud/50\% clear. (a) 1110 HST Terra MODIS overpass, (b) 1350 HST Aqua MODIS overpass, (c) 2240 HST Terra MODIS overpass, and (d) 0220 HST Aqua MODIS overpass.

performed. Additionally, one-tailed two-sample Student's $t$ tests were performed to determine whether the difference between dry and wet season varied with overpass time. These statistical tests were performed using Minitab statistical software (Minitab
Inc., State College, Pennsylvania). The Student's $t$ tests were also applied to the image data on a pixel-by-pixel basis in order to evaluate the statistical significance of spatial patterns in diurnal and seasonal cloud cover variations. 

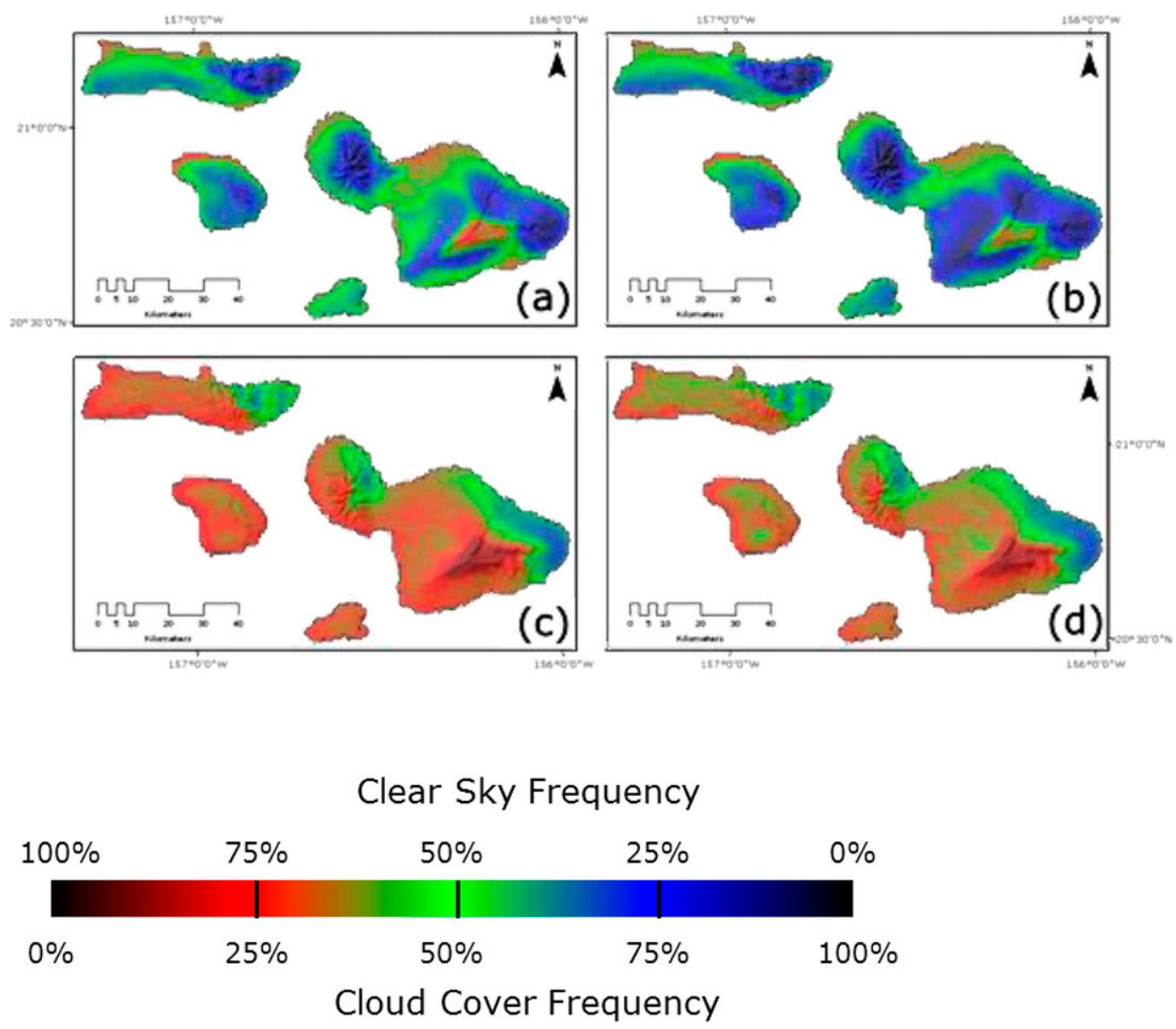

FIG. 3. As in Fig. 2, but over Maui County.

\section{Results}

The map time series of $1-\mathrm{km}$ monthly mean cloud cover frequency for each overpass time are presented in Figs. S1-S4 (figures in the supplemental material are designated by Fig. Sn). These maps were used to discern the spatial patterns of cloud cover and their changes through the diurnal and annual cycles.

\section{a. Spatial patterns}

Derived mean cloud cover statistics showed spatial patterns independent of season and time of day, which are well depicted in the annual mean cloud cover frequency maps. First, cloud cover frequency was higher over land areas with elevations in the elevation range corresponding to the known vertical zone of high cloud occurrence-approximately 600-2200 m (Figs. 2-5). Second, above that zone-that is, for the highest summits on the Hawaiian Islands: Mauna Kea and Mauna Loa on Hawaii, and Haleakalā on Maui-cloud cover frequencies were the lowest in the state (Figs. 2, 3). Finally, cloud cover frequency was generally higher on the windward side (northeast-facing slope) of the mountains than the leeward side (southwest-facing slope) for all islands (Figs. 2-5). This pattern was especially distinct for the nighttime overpasses. However, some exceptions are seen, most notably the Kona region, on the leeward side of Hualalai and Mauna Loa, which had very high cloud cover frequency in the afternoon (Fig. 2b), in agreement with the observed afternoon rainfall maximum in the area (Yang and Chen 2003).

\section{b. Diurnal patterns}

Statewide mean annual cloud cover frequency was higher in the afternoon ( 0.71 at 1350 HST) than in the morning ( 0.59 at 1110 HST) but similar at the two nighttime overpass times (0.37 at 2240 HST and 0.39 at 0220 HST) (Table 1$)$. It was also higher in the daytime than at nighttime (Table 1). The time series of statewide mean monthly cloud cover showed that the diurnal patterns observed above were generally consistent across all months (Fig. 6).

Difference maps showed that trends in the diurnal cycle of cloud cover spatially varied across the islands 

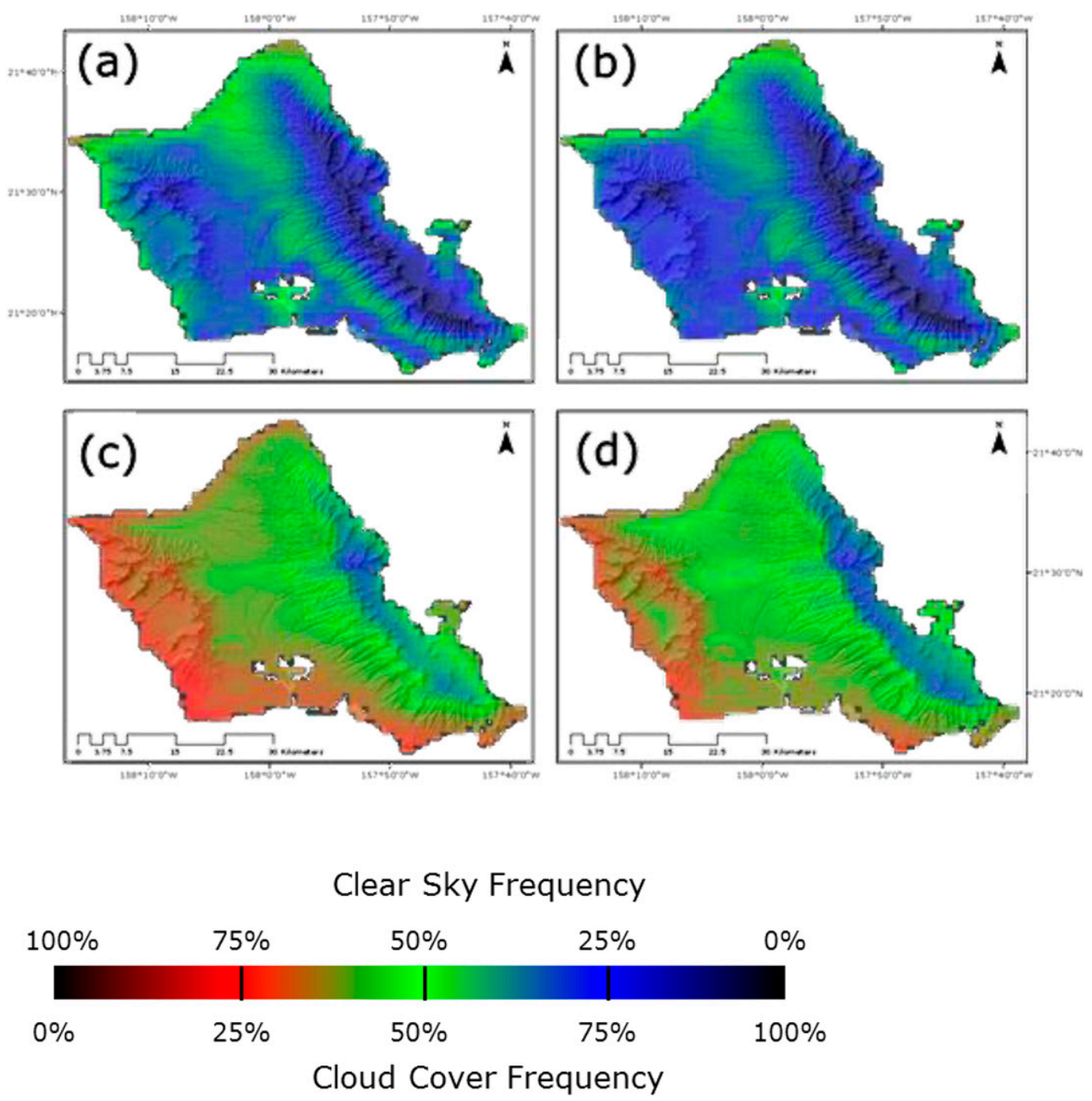

FIG. 4. As in Fig. 2, but over Honolulu County.

(Figs. 7-9). Mean monthly cloud cover frequency was higher in the afternoon than in the morning across the islands in the wet season, except around the Hilo region and the southeastern tips of the Molokai and Maui islands (Fig. 7a for January; results not shown for the other wet season months). During the dry season months of May-October, mean monthly cloud cover frequency was higher in the afternoon than in the morning over most of the island of Hawaii and the western sides of the other Islands, but higher in the morning than in the afternoon for eastern tip of the island of Hawaii and most areas of the other Islands (Fig. 7b for July; results not shown for other dry season months). The $p$ value maps indicate statistical significance at the $95 \%$ level on any differences greater than 0.15 (areas in yellow color in Fig. 7 ; the $p$ value maps in Fig. S5).
While statewide mean values were similar between the Aqua and Terra nighttime overpass times, difference maps between the two nighttime mean monthly cloud cover frequencies showed some spatial variations. Cloud cover frequency was higher at 0220 than at 2240 HST over most of the islands from December through April (Fig. 8a for January as an example), but only over certain areas in May, August, October, and November (Fig. 8b for October). These differences, however, were statistically significant at the $95 \%$ level only over limited areas (areas in yellow color in Fig. 8; the $p$ value maps in Fig. S6). The spatial trends of cloud cover frequency differences for June, July, and September were in between these two. The Kona region of the island of Hawaii had higher cloud cover frequency at 2240 than at 0220 HST in all months of the year (Fig. $8 \mathrm{~b}$ for October). In April, 

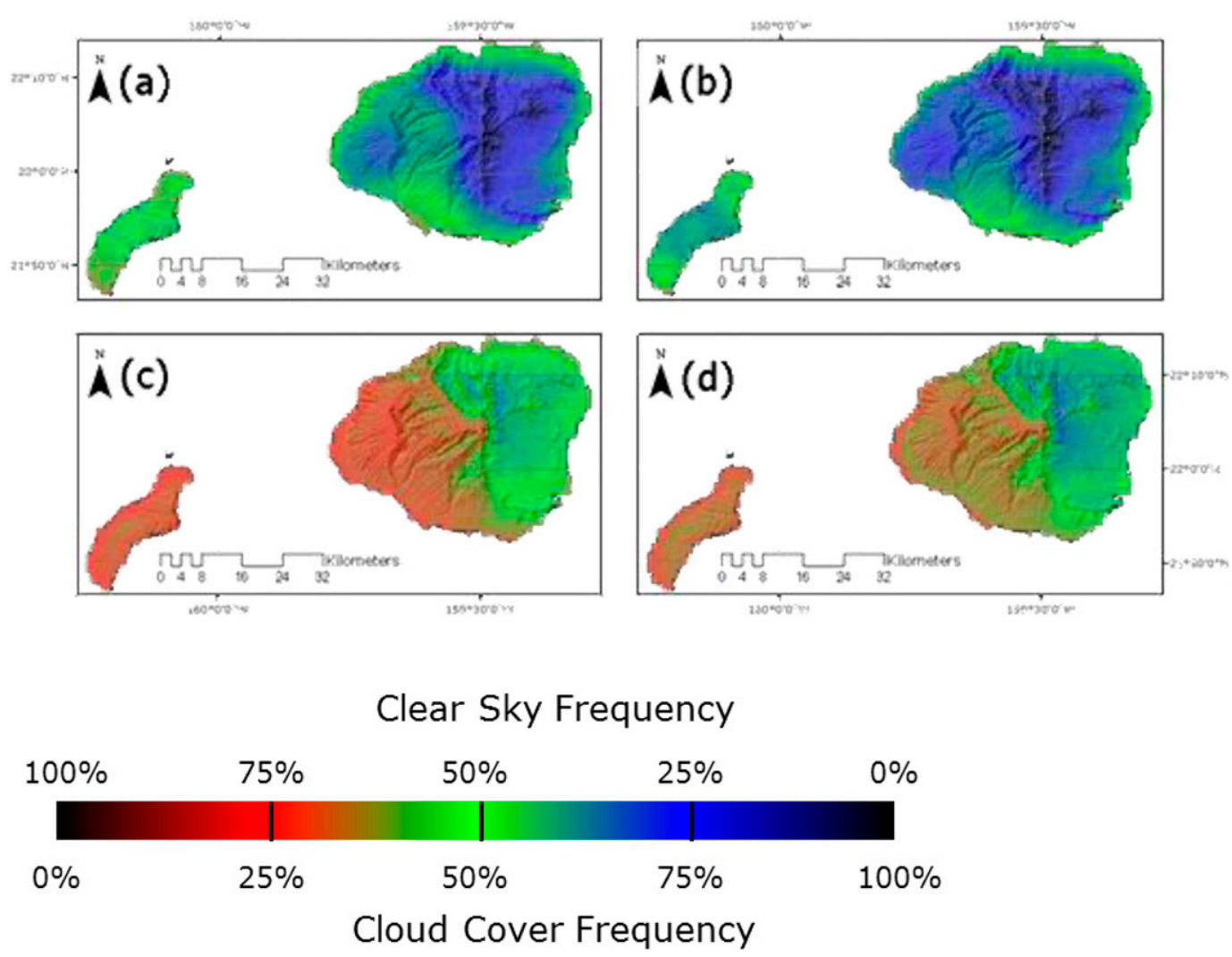

FIG. 5. As in Fig. 2, but over Kauai County.

June, August, September, and October, the magnitude of this localized difference between nighttime overpasses was large $(<-0.2)$ in the Kona region relative to differences between nighttime overpasses across the rest of the Hawaiian Islands, and statistically significant at the $95 \%$ level (Fig. S6b for October).

Daytime versus nighttime (1110 minus 2240 HST) difference maps of mean monthly cloud cover frequency showed that cloud cover frequency was always significantly higher in daytime than at night across the islands in the dry season months, except along the northeast coastlines of all islands and the Kona coast region (Fig. 9b for July; corresponding $p$ value map in Fig. S7b). In the wet season (November-April), differences were smaller and cloud cover frequency was lower in daytime than at night over the central Maui region and the lower slopes of Mauna Kea and Mauna Loa (Fig. 9a for January; corresponding $p$ value map in Fig. S7a). Spatial trends in the 1110 minus 0220 HST difference maps were nearly the same as those presented in Fig. 9 and are thus not shown here. Mean monthly cloud cover frequency at the Aqua daytime overpass time (1350 HST) was generally higher than that at both the Terra (2240 HST) and Aqua (0220 HST) nighttime overpass times across the islands (except for the northeast coastlines) throughout the year (results not shown here).

\section{c. Seasonal patterns}

In general, the dry season months appear to have lower cloud cover frequency than the wet season months. The statewide mean cloud cover frequencies for the dry season months and wet season months were 0.49 and 0.53 , respectively (Table 2). ANOVA results showed that season (dry vs wet) had a significant effect on mean cloud cover frequency ( $p=0.016$ ).

Differences in seasonal cloud cover frequency patterns were related to overpass time (Table 2). Plotting the mean cloud cover frequencies in the dry season versus the wet season separately for each overpass time indicated differences in seasonal patterns in cloud cover frequency based on overpass time (Fig. 10). Figure 10 shows that the dry season months had lower cloud cover frequencies than the wet season months at the nighttime overpass times, which were statistically significant ( $p=0.003$ for 2240 HST and $p=0.001$ for 0220 HST). For the daytime overpasses (1110 and 1350 HST) in contrast, Fig. 10 indicates that for both the Terra MODIS and Aqua MODIS daytime overpasses (1110 and 1350 HST, respectively), cloud cover frequency was lower during the 
TABLE 1. Daytime vs nighttime cloud cover frequency for individual overpasses and combined Terra and Aqua MODIS data [Terra MODIS daytime (1110 HST) + Aqua MODIS daytime (1350 HST)] vs [Terra MODIS nighttime (2240 HST) + Aqua MODIS nighttime (0220 HST)].

\begin{tabular}{lcccr}
\hline \hline & $\begin{array}{c}\text { Terra MODIS } \\
\text { daytime 110 HST }\end{array}$ & $\begin{array}{c}\text { Aqua MODIS } \\
\text { daytime 1350 HST }\end{array}$ & $\begin{array}{c}\text { Terra MODIS } \\
\text { nighttime 2240 HST }\end{array}$ & $\begin{array}{r}\text { Aqua MODIS } \\
\text { nighttime 0220 HST }\end{array}$ \\
\hline Mean (S.E.) & $0.59(0.02)$ & $0.71(0.01)$ & $0.37(0.03)$ & $0.39(0.03)$ \\
\hline
\end{tabular}

wet season than the dry season. Student's $t$ tests showed that at both the Terra MODIS daytime overpass times, statewide mean cloud cover frequencies during the wet and dry season months were not significantly different ( $p=0.914$ for 1110 HST and $p=0.765$ for 1350 HST).

Figure 11 shows seasonal difference maps of cloud cover frequencies for a daytime (1350 HST) and nighttime (2240 HST) overpass. During the daytime, cloud cover frequency was significantly higher in the dry season than in the wet season on the southwestern sides of the islands and in patches on the windward sides of the mountains (Fig. 11a; Fig. S8a for $p$ value map). At night, cloud cover frequency was significantly lower in the dry season than in the wet season across the islands; frequency differences (dry minus wet) were particularly large, greater than -0.2 , for inland areas of the islands except around the summits of Haleakala, Mauna Kea, and Mauna Loa (Fig. 11b; Fig. S8b for $p$ value map). The only exception to this spatial trend was the Kona coast region, where cloud cover frequency was significantly higher in the dry season (Fig. 11b; Fig. S8b).

\section{Discussion}

\section{a. Spatial variations}

In general, the spatial patterns of cloud cover frequency are consistent with our understanding of cloud-generating processes over the islands. Clouds are most abundant along in areas with persistent upslope winds, especially within the vertical zone delimited by the lifting condensation level ( $\sim 600 \mathrm{~m}$ ) — the height to which surface air must be lifted to reach saturation - and the trade wind inversion level $(\sim 2200 \mathrm{~m})$ - where lifting is halted by buoyancy effects (Loope and Giambelluca 1998). Upslope winds are found on the east- and northeast-facing (windward) slopes and, where topographic blocking, flow convergence, and/or thermal effects play large roles, on slopes facing in other directions. Examples of the latter are west-northwest- and south-southeast-facing slopes of Haleakalā on Maui, the southeast-facing slope of Mauna Loa (Kau District), and the west-facing slope of Mauna Loa (Kona region).

\section{b. Diurnal and seasonal variations}

Over tropical oceans and atolls, the diurnal cycles of cloud and rainfall frequency generally exhibit early morning maxima (Schroeder et al. 1977). Over larger oceanic islands in the tropics, thermally driven variations in local wind regimes occur that affect diurnal variation and seasonality in cloud cover. The daytime (especially afternoon) maximum cloud cover frequency and the annual cycle in daytime cloud cover frequency seen in Fig. 6 can be explained by interactions between synoptic-scale winds and local thermal effects. Trade winds occur over the Hawaiian Islands with a frequency of around $95 \%$ during the summer months and around $75 \%$ for the winter months (Garza et al. 2012). Winds are stronger over the islands during the day as a result of vertical mixing caused by daytime heating of the land (Giambelluca et al. 2013). During the day, mixing transports horizontal momentum downward, increasing wind speed, while at night, under stable atmospheric conditions, surface winds diminish. As a result, during trade wind conditions, orographic lifting and cloud development over windward slopes are enhanced during the day and progress through the daytime hours-hence, greater cloud cover in the afternoon than in the morning.

Seasonality in the wind regime, cloud cover, and rainfall in the islands is largely the result of the intrusion of midlatitude cyclonic disturbances into the region, which occurs almost exclusively during November-April. Especially during November-February, trade winds are frequently interrupted by these disturbances, and the afternoon cloudiness peak is less prominent (Fig. 6). The trade wind inversion is also less persistent in winter than in summer because of the effects of these wintertime disturbances (Giambelluca et al. 1986). At night, when trade winds and accompanying windward orographic lifting are suppressed, other influences on cloud generation take on greater importance. Wintertime cyclonic disturbances

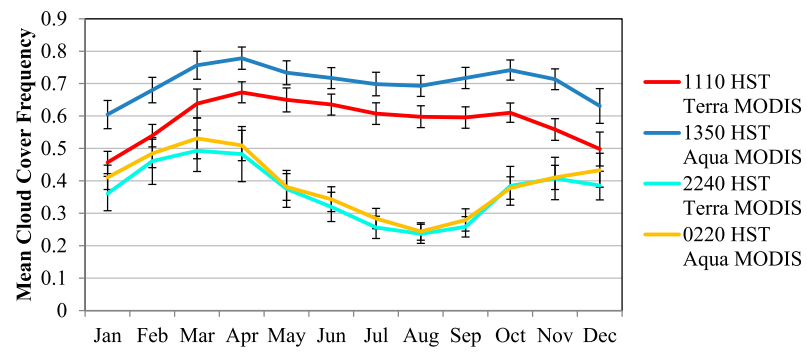

FIG. 6. Monthly time series of mean cloud cover frequencies over the main Hawaiian Islands at all four MODIS overpass times. Error bars represent standard errors. 

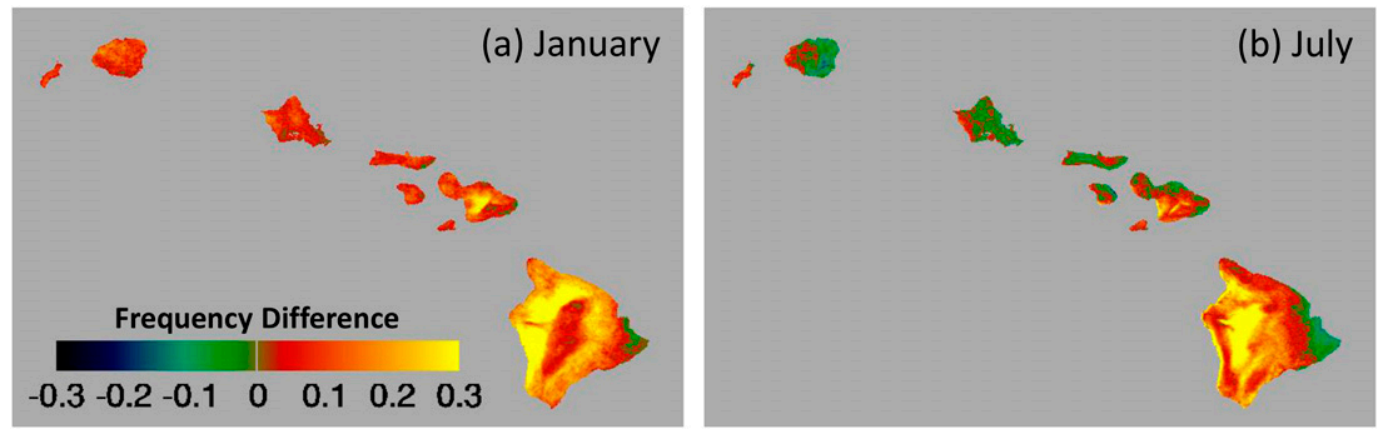

FIG. 7. Afternoon vs morning (1350 minus 1110 HST) differences in mean monthly cloud cover frequencies for (a) January and (b) July.

can produce widespread cloud, affecting both daytime and nighttime cloud cover, but the effect on seasonality is greater at night when trade wind-generated lifting is less important over the islands.

Spatial variations in the diurnal cycle of cloud cover reflect differences in the relative strength of synopticscale and local-scale wind effects and variations in the direction and magnitude of diurnally varying local winds, all of which are also affected by season. The afternoon cloud cover peak, for example, is strongest on the leeward half of the island of Hawaii. With its large areal extent, cloud-generating processes are increasingly influenced by daytime heating as air flows across the island (Fig. 7). The generally higher cloud cover throughout the day compared with night is accentuated in summer (Fig. 9), when land heating is strongest and cyclonic disturbances are rare. In some areas, primarily leeward parts of the islands, daytime cloud cover is lower in the wet season than the dry season (Fig. 11), which we believe is a result of reduced convection from land heating.

\section{c. Correspondence with rainfall patterns}

\section{1) SPATial PATterns AND KonA WeAther}

The patterns in cloud cover frequency over the Hawaiian Islands generally correspond with known rainfall patterns over the state. Annual mean rainfall is generally high on windward (northeast) mountain slopes, and low in leeward (southwestern) lowlands and on summits of high mountains (Giambelluca et al. 2013). Similarly, the annual mean cloud cover frequency results for all the main Hawaiian Islands show higher cloud cover frequency on the windward sides of mountains and lower cloud cover frequency on the leeward sides of the mountains. Additionally, the areas of lowest cloud cover were above the trade wind inversion at the summits of Haleakalā, Mauna Loa, and Mauna Kea. Overall, the leeward/windward and elevational gradients in cloud cover parallel the observed rainfall patterns.

The observed mean cloud cover frequency corresponds with the known unique rainfall pattern on the north and south Kona districts of the island of Hawaii (Giambelluca et al. 2013). While the leeward sides of mountains are generally dry, the Kona districts of Hawaii have a narrow belt of high rainfall as a result of unique airflow patterns in the region (Fig. 12; Giambelluca et al. 2013). In addition to the persistent rainfall, this area also has more rain in the summer than other seasons and has an afternoon rainfall peak (Giambelluca et al. 2013). Corresponding with the observed rainfall pattern, annual mean cloud cover frequency is higher in the north and south Kona regions,
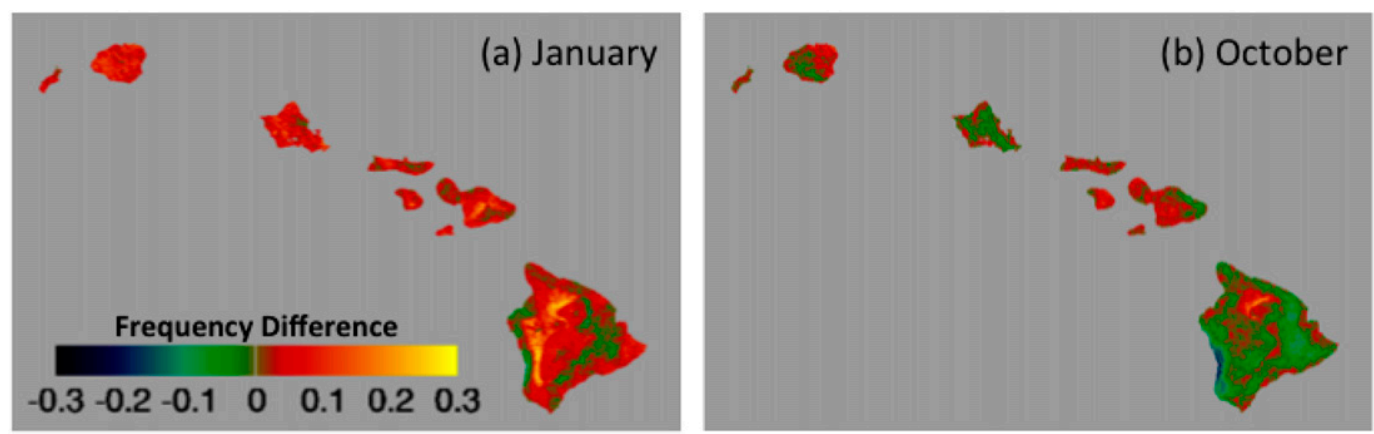

FIG. 8. Nighttime vs nighttime (0220 minus $2240 \mathrm{HST}$ ) differences in mean monthly cloud cover frequencies for (a) January and (b) October. 

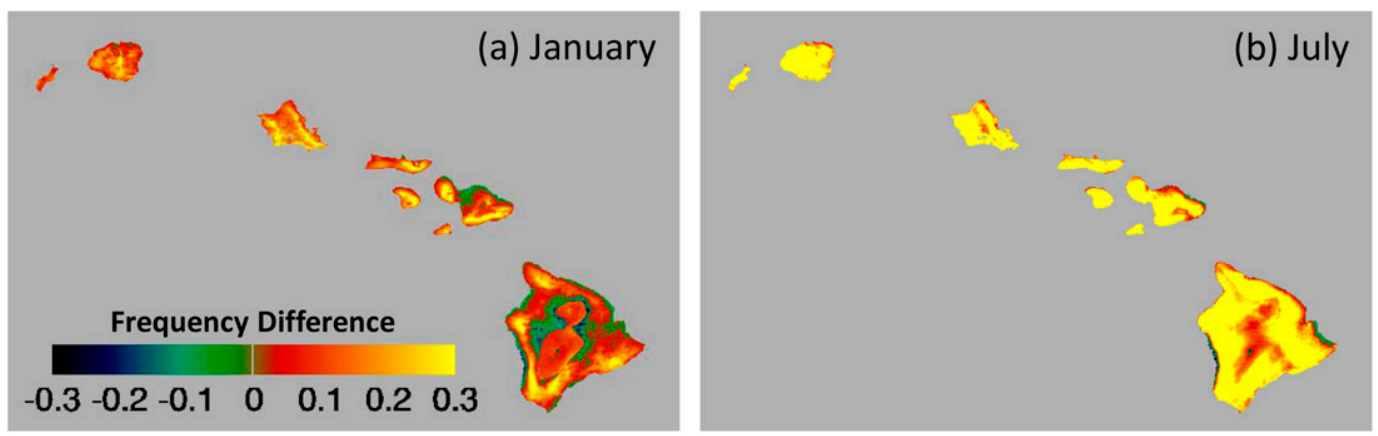

FIG. 9. Daytime vs nighttime (1110 minus 2240 HST) differences in mean monthly cloud cover frequencies for (a) January and (b) July.

and this increased cloud cover seems to be most distinct at the daytime MODIS overpasses (Figs. 2a,b). The highest cloud cover in this region is observed in the afternoon, which is in accordance with the observed afternoon rainfall maximum in the area (Fig. 2b).

\section{2) SEASONAl PATTERNS AND DECEMBER- JANUARY MINIMUM}

The annual cycle of cloud cover frequency generally corresponds to the expected dry season (less cloudy)/wet season (more cloudy) designations, in particular, at nighttime (Fig. 10). The dry season months of May-October generally have lower rainfall than the wet season months of November-April, especially for the drier leeward and high elevation areas (Giambelluca et al. 2013).

Despite being in the middle of the wet season, December and January have the lowest cloud cover frequency for both daytime overpasses and low cloud frequency relative to other wet season months at the two nighttime overpasses (Fig. 6). This apparent conflict between rainfall and cloud cover can be explained by the episodic character of rainfall in these months. This part of the annual cycle is strongly affected by midlatitude disturbances, some of which produce heavy rainfall (Sanderson 1993). During this part of the year, when heavy rain events are not taking place, trade winds are often suppressed and clear skies prevail in areas with otherwise nearly continuous cloud cover. December and January are the months when obtaining daytime cloudfree observations is most probable.

\section{3) DIURNAL PATTERNS}

While diurnal patterns in rainfall vary across the Hawaiian Islands (e.g., the Kona district), the chance of rain is generally higher at night and in the early morning (between 2000 and 0800) than during the late morning and afternoon (Leopold 1949; Chen and Nash 1994; Chen and Feng 1995; Wang and Chen 1998; Li and
Chen 1999). The statewide mean cloud cover frequencies derived in this study were different from this diurnal rainfall pattern and were lower at the nighttime overpasses (2240 and 0220 HST, respectively) than during the daytime overpasses (1110 and 1350 HST, respectively), and the overpass time with the highest cloud cover frequency was the Aqua MODIS daytime (afternoon) overpass at 1350 HST. This discrepancy could have several possible explanations. Cloud frequency is known to be an imperfect predictor of precipitation frequency (Casey et al. 2007), much less precipitation amount. If we assume that both the estimated diurnal cycles of cloud frequency and rainfall amount are not seriously flawed, then this mismatch suggests that, on average, nighttime clouds produce more frequent and/ or more intense rainfall than daytime clouds.

The spatial patterns depicted in our difference maps of mean monthly cloud cover frequencies corresponded well with those described by Schroeder et al. (1977) in section 2a. First, windward (northeast) coastal areas showed little difference in cloud cover frequency between daytime and nighttime in July (Fig. 9b), which is supported by the results of Schroeder et al. (1977). In some windward coastal areas on the islands of Hawaii and Maui, it is slightly cloudier during nighttime than daytime in July (Fig. 9b). Somewhat surprisingly, significant areas have higher cloud frequency in the morning than the afternoon, especially in July (Fig. 7b). Much of the area exhibiting this characteristic is

TABLE 2. Dry vs wet season mean cloud cover frequencies (standard errors in parentheses) for all four MODIS overpasses pooled and individual overpasses.

\begin{tabular}{lcc}
\hline \hline & Dry season & Wet season \\
\hline All four overpasses & $0.49(0.20)$ & $0.53(0.15)$ \\
Terra MODIS daytime 1110 HST & $0.62(0.01)$ & $0.56(0.03)$ \\
Aqua MODIS daytime 1350 HST & $0.72(0.01)$ & $0.69(0.03)$ \\
Terra MODIS nighttime 2240 HST & $0.31(0.03)$ & $0.43(0.02)$ \\
Aqua MODIS nighttime 0220 HST & $0.32(0.02)$ & $0.46(0.02)$ \\
\hline
\end{tabular}




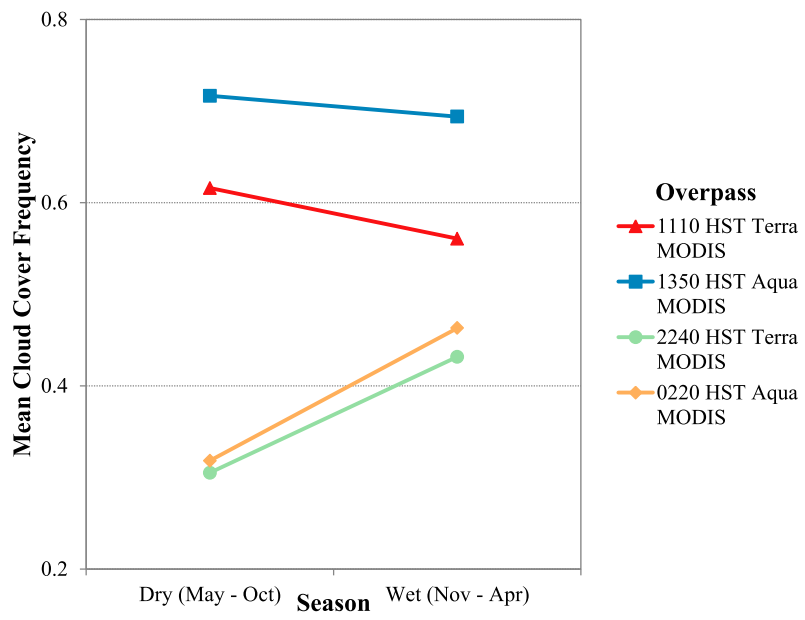

FIG. 10. Interaction plot displaying the interaction between overpass time and season on mean cloud cover frequency.

composed of east-facing slopes that receive greater morning insolation than other areas and are thus more affected by land heating in the morning. Second, our difference maps showed larger diurnal cloudiness variation in windward upland areas than in windward coastal areas, and nighttime was less cloudy than daytime in windward upland areas (Fig. 9). These patterns are supported by Schroeder et al. (1977), who also found a greater diurnal variation in upland windward areas and higher cloud frequency in the daytime than in the nighttime in July. Finally, leeward areas of the islands were generally cloudier during the daytime than the nighttime in July (Fig. 9b) (Schroeder et al. 1977).

\section{d. Possible data limitations}

The Terra MODIS and Aqua MODIS cloud mask algorithms are essentially the same (Ackerman et al. 2008). Results between the two satellites are offset by $2 \%$ globally; however, it is difficult to assess whether these differences are due to variances in instrument performance or reflect real diurnal variation in cloud amount (Ackerman et al. 2008). For the purposes of this study, it was assumed that differences in observed cloud frequency between overpass times were not significantly influenced by systematic biases affecting data derived from the Terra versus Aqua MODIS cloud mask products.

As mentioned previously, adjustments for nighttime data were made to the algorithm that translated MODIS cloud cover designations into binary cloudy/clear. These adjustments were to reduce well-documented errors in the MODIS cloud mask product over the Hawaiian Islands. Specifically, the nighttime surface temperature test performed by the MODIS cloud mask algorithm caused false cloud detection over coastal lowlands up to $2000 \mathrm{~m}$ over the Hawaiian Islands. The changes to the nighttime algorithm reduced the false overclouding as a result of the surface temperature test. However, it is possible that the algorithm changes made to reduce false cloud detection could have also reduced the detection of real clouds. As a result, there could be a small bias in the nighttime cloud cover frequency data toward lowerthan-actual cloud cover frequency.

One of the drawbacks of using MODIS data to determine cloud cover frequency is that the data are temporally limited. Together, the two MODIS sensors only pass over the Hawaiian Islands four times per day. While high-spatial-resolution MODIS cloud mask data are able to illuminate spatial patterns of cloud cover in detail, it is difficult to discern the diurnal cloud cover cycle using only four data points per day. The Geostationary Operational Environmental Satellite (GOES) system has been acquiring image data every $15 \mathrm{~min}$ at a 4-km spatial resolution. By fusing cloud analyses derived from MODIS and GOES, a cloud cover frequency time series with both high spatial and temporal resolution can be derived (Giambelluca et al. 2014). Examining this merged dataset would allow for a more complete
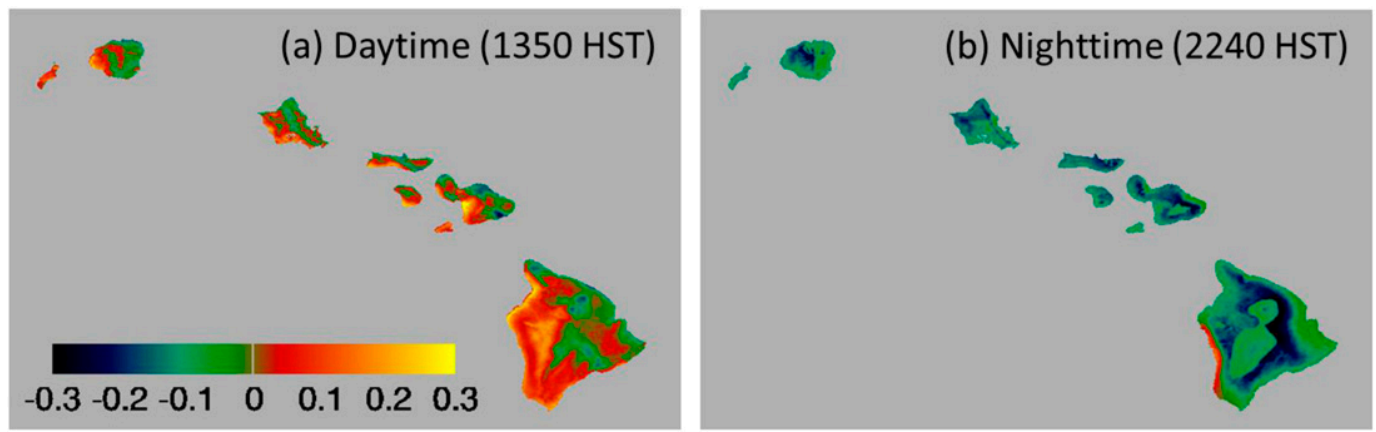

FIG. 11. Seasonal (dry minus wet) differences in mean monthly cloud cover frequencies for (a) daytime (1350 HST) and (b) nighttime (2240 HST). 


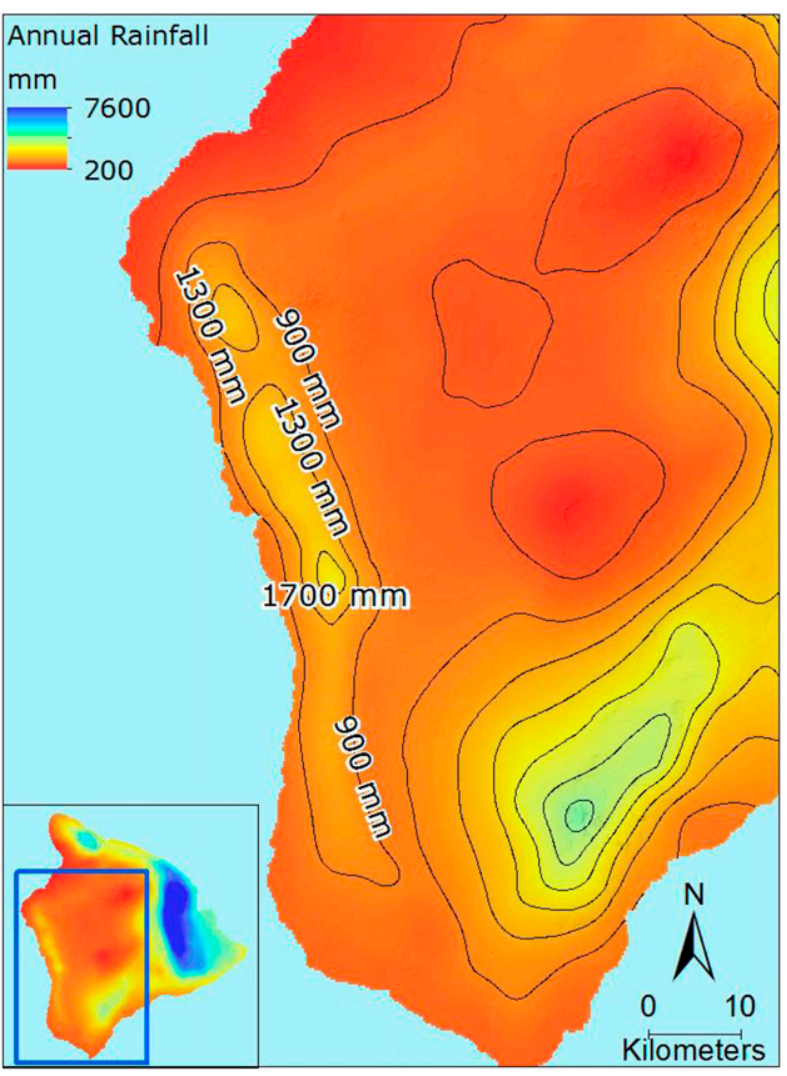

FIG. 12. Narrow band of increased rainfall in the north and south Kona regions of Hawaii (data source: Giambelluca et al. 2013).

picture of the diurnal cycle in cloud cover frequency and illuminate the relationship between cloud cover frequency and rainfall.

\section{Summary and conclusions}

In this study, cloud cover frequency statistics were derived from MODIS 1-km daily cloud cover data and analyzed to determine spatial, diurnal, and seasonal patterns in cloud cover over the main Hawaiian Islands in detail. This study provided the first high-spatial-resolution cloud cover dataset in Hawaii. The key characteristics of cloud cover found in this study are as follows:

- Cloud cover frequency generally increases with elevation until roughly $2000 \mathrm{~m}$, above which it is usually clear.

- The lowest cloud cover frequencies were observed over the high elevation areas (above the trade wind inversion layer) on the islands of Maui and Hawaii.

- Cloud cover frequency systematically varied in relation to the facings of slopes; cloud cover frequency was higher on the windward (northeastern) sides of the mountains than on the leeward (southwestern) sides of the mountains.
- The dry season months (May-October) had lower cloud cover frequency than the wet season months (November-April) at the two nighttime overpasses, whereas cloud cover frequency was not significantly different between the dry and wet seasons at the two daytime overpasses.

- Irrespective of season, the afternoon was generally cloudier than the morning.

- Mean cloud cover frequency was similar at the two nighttime overpasses regardless of season.

- Nighttime cloud cover frequency was lower than afternoon cloud cover throughout the year and lower than morning cloud cover frequency for most of the year.

- January and December were the months with the lowest cloud cover frequencies out of the year.

- The diurnal cycle of cloudiness is spatially complex and depends on local topography and exposure.

- Season also influences the diurnal cycle; for example, morning is cloudier than afternoon in July, while afternoon is cloudier than the morning in January for both windward coasts and upland areas.

Acknowledgments. This study was supported by a Pacific Island Climate Science Center Graduate Student Fellowship award to M. L. Barnes, a U.S. Army Corps of Engineers Honolulu District and State of Hawaii Commission on Water Resource Management Cooperative Agreement (T. Giambelluca, P.I.), and a U.S. Department of Agriculture McIntire-Stennis Research Grant (T. Miura, P.I.). The authors thank Thomas Schroeder for the advice on cloud-related processes on the island of Hawaii.

\section{REFERENCES}

Ackerman, S. A., K. I. Strabala, W. P. Menzel, R. A. Frey, C. C. Moeller, and L. E. Gumely, 1998: Discriminating clear sky from clouds with MODIS. J. Geophys. Res., 103, 3214132 157, doi:10.1029/1998JD200032.

— , and Coauthors, 2006: Discriminating clear-sky from cloud with MODIS algorithm theoretical basis document (MOD35), version 5.0. University of Wisconsin-Madison Doc., 125 pp. [Available online at http://modis-atmos.gsfc.nasa.gov/_docs/ MOD35:MYD35_ATBD_C005.pdf.]

, R. E. Holz, R. Frey, E. W. Eloranta, B. C. Maddux, and M. McGill, 2008: Cloud detection with MODIS. Part II: Validation. J. Atmos. Oceanic Technol., 25, 1073-1086, doi:10.1175/ 2007JTECHA1053.1.

— Product. NASA MODIS Adaptive Processing System, Goddard Space Flight Center, doi: 10.5067/MODIS/MOD35_L2.006.

Casey, S. P. F., D. E. Andrew, and C. Schumacher, 2007: Frequency of tropical precipitating clouds as observed by the Tropical Rainfall Measuring Mission Precipitation Radar and ICESat/ 
Geoscience Laser Altimeter System. J. Geophys. Res., 112, D14215, doi:10.1029/2007JD008468.

Chen, Y.-L., and A. J. Nash, 1994: Diurnal variations of surface airflow and rainfall frequencies on the island of Hawaii. Mon. Wea. Rev., 122, 34-56, doi:10.1175/1520-0493(1994)122<0034: DVOSAA $>2.0 . \mathrm{CO} ; 2$.

—, and J. Feng, 1995: The influences of inversion height on precipitation and airflow over the island of Hawaii. Mon. Wea. Rev., 123, 1660-1676, doi:10.1175/1520-0493(1995)123<1660: $\mathrm{TIOIHO}>2.0 . \mathrm{CO} ; 2$.

Frey, R. A., S. A. Ackerman, Y. Liu, K. I. Strabala, H. Zhang, J. R. Key, and X. Wang, 2008: Cloud detection with MODIS. Part I: Improvements in the MODIS cloud mask for collection 5. J. Atmos. Oceanic Technol., 25, 1057-1072, doi:10.1175/ 2008JTECHA1052.1.

Garza, J. A., P.-S. Chu, C. W. Norton, and T. A. Schroeder, 2012: Changes of the prevailing trade winds over the islands of Hawaii and the North Pacific. J. Geophys. Res., 117, D11109, doi:10.1029/2011JD016888.

Giambelluca, T. W., and T. A. Schroeder, 1998: Climate. Atlas of Hawaii, 3rd ed. S. P. Juvik and J. O. Juvik, Eds., University of Hawai'i Press, 49-59.

—, M. A. Nullet, and T. A. Schroeder, 1986: Rainfall atlas of Hawaii. Hawaii Dept. of Land and Natural Resources Rep. R76, $267 \mathrm{pp}$

- Q. Chen, A. G. Frazier, J. P. Price, Y.-L. Chen, P.-S. Chu, J. K. Eischeid, and D. M. Delparte, 2013: Online rainfall atlas of Hawai'i. Bull. Amer. Meteor. Soc., 94,313-316, doi:10.1175/ BAMS-D-11-00228.1.

_- and Coauthors, 2014: Evapotranspiration of Hawai'i. Hawaii Commission on Water Resource Management Final Rep., $168 \mathrm{pp}$.

Ju, J., and D. P. Roy, 2008: The availability of cloud-free Landsat ETM+ data over the conterminous United States and globally. Remote Sens. Environ., 112, 1196-1211, doi:10.1016/ j.rse.2007.08.011.

Leopold, L. B., 1949: The interaction of trade wind and sea breeze, Hawaii. J. Meteor., 6, 312-320, doi:10.1175/ 1520-0469(1949)006<0312:TIOTWA > 2.0.CO;2.

Li, J., and Y. L. Chen, 1999: A case study of nocturnal rain showers over the windward coastal region of the island of Hawaii. Mon. Wea. Rev., 127, 2674-2692, doi:10.1175/ 1520-0493(1999)127<2674:ACSONR>2.0.CO;2.

Loope, L. L., and T. W. Giambelluca, 1998: Vulnerability of island tropical montane cloud forests to climate change, with special reference to East Maui, Hawaii. Climatic Change, 39, 503-517, doi:10.1023/A:1005372118420.

Pincus, R., S. Platnick, S. A. Ackerman, R. S. Hemler, and R. J. P. Hofmann, 2012: Reconciling simulated and observed views of clouds: MODIS, ISCCP, and the limits of instrument simulators. J. Climate, 25, 4699-4720, doi:10.1175/ JCLI-D-11-00267.1.

Platnick, S., M. D. King, S. A. Ackerman, W. P. Menzel, B. A. Baum, J. C. Riedi, and R. Frey, 2003: The MODIS cloud products: Algorithms and examples from Terra. IEEE Trans. Geosci. Remote Sens., 41, 459-473, doi:10.1109/TGRS.2002.808301.

Running, S. W., R. R. Nemani, D. L. Peterson, L. E. Band, D. F. Potts, L. L. Pierce, and M. A. Spanner, 1989: Mapping regional forest evapotranspiration and photosynthesis by coupling satellite data with ecosystem simulation. Ecology, 70, 10901101, doi:10.2307/1941378.

Sanderson, M., 1993. Prevailing Trade Winds: Climate and Weather in Hawai' $i$. University of Hawai'i Press, 127 pp.

Sano, E. E., L. G. Ferreira, G. P. Asner, and E. T. Steinke, 2007: Spatial and temporal probabilities of obtaining cloud-free Landsat images over the Brazilian tropical savanna. Int. J. Remote Sens., 28, 2739-2752, doi:10.1080/01431160600981517.

Schroeder, T. A., B. J. Kilonsky, and B. N. Meisner, 1977: Diurnal variation in rainfall and cloudiness. University of Hawaii Water Resources Research Center Tech. Rep. $112,67 \mathrm{pp}$

Strabala, K., 2008: MODIS cloud mask user's guide. NASA MODIS Atmosphere Rep., 32 pp.[Available online at http:// modis-atmos.gsfc.nasa.gov/_docs/CMUSERSGUIDE.pdf.]

Wang, J. J., and Y.-L. Chen, 1998: A case study of trade-wind rainbands and their interaction with the island-induced airflow. Mon. Wea. Rev., 126, 409-423, doi:10.1175/1520-0493(1998)126<0409: ACSOTW $>2.0 . C O ; 2$

Wylie, D., D. L. Jackson, P. W. Menzel, and J. J. Bates, 2005: Trends in global cloud cover in two decades of HIRS observations. J. Climate, 18, 3021-3031, doi:10.1175/JCLI3461.1.

Yang, Y., and Y.-L. Chen, 2003: Circulations and rainfall on the lee side of Hawaii during HaRP. Mon. Wea. Rev., 131, 2525-2542, doi:10.1175/1520-0493(2003)131<2525:CAROTL > 2.0.CO;2. , S.-P. Xie, and J. Hafner, 2008a: Cloud patterns lee of Hawaii Island: A synthesis of satellite observations and numerical simulation. J. Geophys. Res., 113, D15126, doi:10.1029/2008JD009889. , and $2008 \mathrm{~b}$ : The thermal wake of Kauai Island: Satellite observations and numerical simulations. J. Climate, 21, 4568-4586, doi:10.1175/2008JCLI1895.1. 